\title{
Moral Competence and Foundations of Moral Judgment. An Empirical Exploration of Concepts and New Possibilities for Understanding
}

\author{
Bogdan Popoveniuc \\ (University Stefan cel Mare of Suceava/West University of Timişoara; Romania; bpopoveniuc@usm.ro) \\ ORCID: 0000-0002-4615-7594
}

\begin{abstract}
The present study examines the relation between the moral intuitions proposed by the 'Moral Foundations Theory' according to J. Haidt and the moral orientations in relation with moral competence, as described by the 'Dual-Aspect Model of Moral Behaviour' according to G. Lind.

It is an empirical exploration of the relation between the five foundational domains (and/ or the corresponding two higher-order clusters) and the moral orientations, as this results from the theoretical assumptions of both theories, and the influence on and of the moral competence on these aforementioned relations. The shared affective and, at the same time, habitual characteristics of moral intuitions and moral orientations, although based on different theories (intuitionism, respectively, cognitivism) should converge in a dynamic relationship.

The basic motivation is the need to overcome the affective-cognitive disjunction in the study of moral judgment, which is artificial. The human (moral) reasoning is always a situated and situating one, in a symbolic narrative universe, in which the cognitive-affective dichotomy forms a dynamic unity. This overstated dichotomy is only a methodological necessity, but unfortunately hypostasized in an explanatory mechanism that leads to the impermissible simplification of the phenomenon that it seeks to understand.

The empirical results confirm the limits of both cognitive and intuitions paradigms and advocates for a more nuanced and dynamic approach in understanding the moral judgment within a more comprehensive conception on human personality. Finally, the implications for the contemporary psychology' paradigm are discussed.
\end{abstract}

Keywords: moral competence; moral judgment; moral intuitions; moral orientations; axiology.

\section{Introduction}

The study of the mechanisms of moral judgment is both a challenging and a difficult task, as the moral functioning involves the cooperation of complex interrelated components. Even the most used and praised cognitive theories on moral judgment are based on more comprehensive psychological constructs, which exceeds by far what is 
usually understood by cognition. The neo-Kohlbergian approach is based on moral sensitivity - involving perception, sensitivity and interpretation of situations -, the moral judgment - related to reasoning, judgment and reflection -, the moral motivation -encompassing motivation and concentration -, and the moral character - linked to initiation and completion of action (Rest 1983).

The constraints imposed by the contemporary research paradigm, methodological limitations and practical aspects make it difficult to verify complex models involving emotional, cognitive, value-based and motivational aspects, which involve self-narrative building upon a complex fabric of cultural and ideological meanings. For this reason, studies on moral judgments are often limited either to highlighting particular components of them, or to studying the manifestation of moral behavior in a particular context.

For example, the dominant paradigm in the study of reasoning, judgments, and decision-making takes for granted the (conflicting) relationship between affectivity and reason. The main line of approach towards moral judgments opposes the emotions to reason, and defines the methods of investigation. Depending on the stimulus, the proposed prototypical situations highlight one or the other of these dimensions, as they are framed within the experiment task (Ellemers, van der Toorn, Paunov, \& van Leeuwen 2019).

The different models of morality that have appeared in the literature over the years may be a direct consequence of the different moral situations considered by the researchers who have proposed them: observe humans as they try to solve complex moral dilemmas, and you are likely to propose a model of morality that relies heavily on high-level reasoning; ask them how they feel about disgusting immoral acts, and you are likely to conclude that morality is all about gut reactions that require little rational deliberation (Monin, Pizarro, \& Beer 2007b, 223; see also Monin, Pizarro, \& Beer 2007a).

In other terms, the research within the "moral domain" is threatened by the effect of the self-fulfilling prophecy phenomenon (Jussim 1986). Studies on the functioning of the moral judgment are limited to particular relationships and interactions within these complex models. In terms of values, motivations, emotions or attitudes, the problem of researching the role of affectivity in relation to moral reasoning and moral judgment has certain intrinsic methodological limitations.

Most of the studies do not set out to check this dichotomy from the beginning, and, hence, limit $a b$ initio the possibility of identifying more nuanced relationships. Even thought, they seem to justify, rather, a perspective based on the idea of continuity between "intuition" and "reasoning" as "two facets of the same process which spans from fast, immediate, and certain answer to slow, conscious and elaborate judgments" (Dellantonio \& Job 2012, 241).

The present study aims to highlight possible relationships between intuitive aspect (mostly affective, pre- or subconscious, and also involving automatic reasoning) and cognitive aspect (which are mostly based on post-hoc conscious reasoning) of the moral judgment. The relationship between affectivity (understood as moral intuition) and 
reason - or the moral reasoning - is not necessarily either disjunctive, or contradictory. The gap between theoretical approaches is so big, that it seems they are dealing with different phenomena. These heterogeneous perspectives compose a dismantled imagine of human moral psychology. The picture of human moral is painted in flashy colors of the clashing self-subsistent monolithic and conflicting mechanisms (cognitive, affective, motivational etc.). Greene's theory on moral judgment is reflecting this state of affairs, by starkly opposing emotion (through the lens of a deontological-prone judgment) to cognition (utilitarian-prone judgments), as "competing subsystems in the brain" (Green et al. 2004). The images on moral judgment are inevitably half-done, as the two main theories (also used in this study) - the Moral Foundations Theory (MFT) and the Cognitive Development Theory (CDT) - highlight two partial images on moral judgment:

\begin{tabular}{|l|l|l|l|l|l|l|l|}
\hline MFT & event & $\rightarrow$ & intuition & $\rightarrow$ & judgment & $\leftrightarrow$ & post hoc reasoning \\
\hline CDT & event & $\rightarrow$ & ? & $\rightarrow$ & ante hoc reasoning & $\rightarrow$ & judgment \\
\hline
\end{tabular}

But, if the assumptions of the two models are merged, it can get presumably a better image of the moral reasoning, which seems to suggest the following logical flow:

event $\rightarrow$ [interpretation (automatic ante hoc reasoning)] $\rightarrow$ intuitive judgment (affective aspect) $\rightarrow$ [post hoc reasoning (motivated or reflective)] $\rightarrow$ moral judgment (cognitive aspect).

\section{Theoretical Background of the Research}

\subsection{The Moral Foundations Theory (MFT)}

The Moral Foundations Theory (Haidt 2001, 2013; Haidt \& Graham 2007; Graham et al. 2011) proposes a nativist, intuitionist and pluralistic perspective on morality. It starts from the evolutionary premise that there is a nativist pre-organization of the human mind that facilitates the acquisition of behaviors, norms and values, which are involved in adapting to a set of recurring social problems. They have a vital function of controlling and suppressing natural selfishness in order to make social life possible. The five main foundations of morality, based on quick and automatic moral intuitions, are those related to "harm/care," "fairness/reciprocity," "ingroup/loyalty," "authority/respect," and "purity/sanctity". The first two foundations collapse in personal-individualizing category, as they are oriented on the rights and liberties of all individuals, while the last three in group-binding, focusing on the group cohesion). Beside these, the authors have also identified other possible candidate dichotomies such as "liberty/oppression," "efficiency/ waste," and "ownership/theft" (Graham et al. 2013). I use also the three clusters version of collapsing the moral foundations as suggested by the original source of MFT Shweder's (1997) "big three" of morality: autonomy ("harm" \& "fairness), community ("loyalty" 
\& "authority"), and divinity ("spirituality"), because the fifth foundation Spirituality is heavily loaded with religious significance

The relevance of this theory for the present study is that it highlights the active role of the sets of values (rooted in the same moral foundations) to which the individual adheres to, and in relation to the way he or she reasons. In the Moral Foundations Questionnaire, the authors use two sets of items. The first set includes relevance-items, which measure personal theories (self-theory) about the moral judgment (the perceptions that an individual's has about his own moral values), the second set are judgment-items, concrete examples about which individual makes moral judgments.

The relevance-items are formulated abstractly by reference to the group - generally family or nation - in order to avoid cultural conflict on certain sensitive issues, e.g., gay rights or the right to bear arms. Judgment scales were added to the relevance ones in order to minimize the impact of the variation; this was based on the set of answers - e.g., a person can consider all aspects as morally relevant - as well as to contextualize the abstract items. These items also have the function to balance the differences between the explicit self-theories related to how one makes moral judgments with the effective moral judgment (Nisbett \& Wilson 1977).

\subsection{Dual-Aspect Theory of Moral Behavior (DATMB)}

Dual-Aspect Theory of Moral Development is rooted in Kohlberg's cognitive theory of moral development. It is based on the principle that moral competence is "the capacity to make decisions and judgments which are moral" (i.e., based on internal principles) and to act in accordance with such judgments" (Kohlberg 1964, 425). Therefore, one might argue that morality cannot be reduced to principles, attitudes, values, intuitions, moral stances, but all of these are involved more or less in the moral judgement. However, in order to reflect individual's free-will and deliberate decision, without which the moral responsibility is a flatus vocis, the structure or the cognitive scheme is essential to underpin the moral orientation. At the same time, affectivity (or emotion) does not come as a complementary, opposite or distinct aspect of cognition, but should be conceived as the secondary aspect of the moral behavior. Within the theory of the dual aspect of moral judgment, proposed by Georg Lind, moral judgment (cognitive dimension) and moral orientation (affective dimension) are two aspects, but not components, of the moral behavior. Moral competence is nothing but the ability to use consistently and differently a certain moral orientation for making moral judgments in different social situations (Lind 2016). In other words, the "virtue" of self-consistent moral behavior or the verticality (read, consistency) of moral character. The more moral I am, the more consistent I am in my judgments (and conduct), in various situations, with different actors and regarding different deeds.

In the research literature, MFT and CDT are two different paradigms, which reflect different psychic phenomena. Whilst MFT aims at the range of social concerns grouped 
semantically (linguistically) around the term "moral," CDT aims to capture the end-point of a process of developing increasingly differentiated thinking about social issues. "On offer, then, are not two functionally equivalent conceptions of the moral domain, but two constructs that are doing different theoretical work in very different theoretical frameworks" (Maxwell \& Beaulac 2013, 378). However, both theories share the same assumption, i.e., that affectivity has a well-defined position in moral judgments and this study tries to see if they converge in this point, as they should.

\section{Literature Review}

The viability of my hypothesis was suggested by the few (and) scattered studies on this topic. The analysis of the literature suggested the possibility of the existence of relations between certain foundations and moral orientations, in relation with the moral competence. The link between the moral foundations and the moral competence seems to be the most documented, mainly by the negative relationship discovered in several studies between social conservatism and the moral competence (measured with either DIT2 or MCT: [Emler 2002; Candee 1976; Fishkin, Kenniston, \& MacKinnon 1973; Lind, Sandberger, \& Bargel 1985; Nassi, Abramowitz, \& Youmans 1983; Raaijmakers, Verbogt, \& Volleberg 1998; Simpson 1987]).

On the other hand, moral competence was found to negatively correlate with the "binding" foundations (Graham, Haidt \& Nosek 2009). However, comparing the populations of America and Israel, Gross (1996) has shown that these differences are considerably tempered when education and socioeconomic status are taken into account, although the samples are relatively small, four groups of about 50 subjects.

The analysis of the research carried out on this topic led to the identification of just three articles that directly address the issue of the relationship between moral competence and moral foundations. Investigating the relationship between psychopathy and moral orientation, Gay, Vitacco, Hackney, Beussink and Lilienfeld (2018) find a positive correlation of moral competence with the foundation of "fairness/reciprocity" and a negative one with "ingroup/loyalty" in one study. However, the second study finds no correlation and the third study finds only a negative correlation between moral competence and the two foundations of "binding" foundations (Gay, Lishner, Vitacco, \& Beussink 2019).

The study made by Trups-Kalne and Dimdins (2017) seems to be the only one that aims to test directly the relationship between moral foundations and moral orientations, and moral competence respectively. obtaining only a negative relationship between moral competence and the "binding" foundation. The study also finds a positive correlation between the arguments corresponding to conventional stage 3 of Kohlberg's model - based on the appeal on solidarity and group cohesion - and the importance given to "binding" foundations. Paradoxically, a negative correlation was noticed between moral 
competence and "fairness". Their conclusion was that the rational-cognitive and socialintuitionist perspectives on moral judgment use different conceptual constructions, the only correlations obtained being opposed, overall, to the theoretical predictions.

The present study intends to answer this challenge and to test this connection between the two sets of constructs - i.e., the moral foundations and the moral orientations, respectively, the moral competence, articulated within two alternative theoretical paradigms which investigate the territory of moral judgments/decisions. It aims to identify the inter-relations between the aspects of relevance (evaluative, i.e., moral values) and the criteria of judgment (moral orientations), which are both related to the capacity of moral reasoning, conceived as the level of moral competence.

The first hypothesis is that the moral competence correlates positively with the "individualising" of moral foundations ("harm/care," "fairness/reciprocity") and, negatively, with "binding" ones ("ingroup/loyalty," "authority/respect," and "purity/sanctity"). Given that the MCT uses judgment items, the correlations of moral competence with judgment subscale should be stronger than that on the relevance subscale.

The second hypothesis is that moral intuitions is related with the moral orientations, a relationship moderated by the level of moral competence as it follows:

(H2.1) The moral orientations corresponding to the conventional stages $(3,4)$ are in a positive relationship with the "biding" foundations;

(H2.2) The moral orientations corresponding to the postconventional stages $(5,6)$ are in a positive relation with the foundations of "individuality";

(H2.3) The correlations between moral orientations and the moral foundations as measured on the judgment subscale are weaker than the measures on the relevance subscale;

(H.2.4) The predicted patterns of correlations are stronger for higher moral competence;

The present study has an exploratory purpose and tone, which is justified partly by the lack of substantial investigation of these relations within the present literature.

\section{Methodology of the Research}

\subsection{Instruments}

Many studies have tried to clarify the relationship between values and moral judgment using various instruments, i.e., Kohlberg's Moral Judgment Interview (Kohlberg 1981, 1984) or Defining Issues Test (Rest, Narvaez, Thoma, \& Bebeau 1999), and Schwartz' Personal Values Questionnaire (SPV) (Schwartz et al. 2012) or Rokeach Value Survey (RVS) (Rokeach 1973) respectively. So far, the results from these studies 
proved inconclusive, with some studies showing no influence at all (Gay et al. 2018), or displaying weak relations (Ostini \& Ellerman 1997), or some partial relations (Helkama 1982; Diessner, Mayton, \& Dolen 1993; Lan, Gowing, Rieger, McMahon, \& King 2010). Other studies have argued for the existence of the mediating function of values - for example, between personality traits, or empathy, and ethical competence (Pohling et al. 2016), whilst others revealed a more systematic relationship (Lan, Gowing, McMahon, Rieger, \& Friz 2008).

Moral foundations were measured using the Moral Foundations Questionnaire (MFQ) proposed by Jesse Graham and Jonathan Haidt, which was based on the MFT (Graham et al. 2011). Moral orientations and moral competence were measured using "Moral Competence Test" (MCT), an instrument developed throughout a 40 years period by Professor Georg Lind, based on a "Dual-Aspect Theory of Morality and Moral Development" (Lind 2016).

Although the instruments of measurement used in these studies are not seen as being convergent, their shared purpose and complementarity made them useful for constructing the research hypotheses, e.g., the consistency discovered between Schwartz's Personal Values Questionnaire (SPV) (Schwartz et al. 2012) and Haidt's dimensions predict unique variance in morality attitudes, behavior, and individual-differences (Feldman 2020). For the purpose of my research, I consider that both of these two instruments have managed to instill the necessary confidence, which is so important when aspiring to have reliable measurements. (In the very recent literature, however, appears studies that question the viability of Moral Foundation instrument). The confidence was directly provided by their background theoretical assumptions, which considered the intertwined relationship between emotion and cognition as key, and how these instruments themselves were constructed to allow the observation and consideration of these both components. I have therefore chosen these two instruments due of their properties and operational value, which make them compatible for the study of the interaction between values (intuitions) and moral judgment.

The MFQ contains two sets of questions: i.e., one based on the assessment of the relevance of the five types of foundations and the other being based on the assessment of judgments made according to them. On the other hand, the MCT aims at measuring the moral competence index, which is based on the assessment of agreement (consistency of answers) with arguments corresponding to the six types of moral orientations inspired by Kohlberg's stage model. MCT also aims at identifying the moral orientation preferred by the respondent.

Therefore, although the two instruments are rooted in distinct theoretical traditions, they both meet at the level of judgment and in relation to the relevance given to moral values. The instruments are complementary in analyzing the image of the interaction between values (intuitions) and judgments, respectively, moral reasoning, although in different ways and on different theoretical backgrounds. At the same time, I have tried 
to investigate whether there was a convergent validity between the moral foundations and the moral orientations. According to the theories on which the instruments are based on, both constructs share the assumption of the innate-cultivated hybrid character of moral judgment. If modular innateness is salient in the case of the MFT, the modular and gradually constructed structure of moral orientations from the theory of CDT could be naturally promoted by such preparedness. This assumption if (indirectly) tested, can be an argument for the convergence of the two theoretical perspectives.

I choose MCT instead of DIT2, because the two instruments measure the affective and cognitive aspects in different ways, although in an integrated or even mixed way. DIT2 measures how consistently (cognitive aspect) the subject prefers (affective aspects of) post-conventional arguments. What is difficult to determine in the case of DIT2 is whether this consistency is due to moral development or simply the desire to defend a certain point of view, because DIT2 is related to the preference of reasoning according to a particular stage (Bataglia, de Morais, \& Lepre 2010). By contrast, the advantage of MCT in measuring the coherence of answers is that it assesses the capacity for moral reasoning independently of the subject's orientation (Lind 2016), i.e., it measures the ability to manage the task of differentiating the quality of arguments regardless of the preference for one action or another (Ishida, 2006).

For both instruments, the official Romanian translations indicated by their respective authors were used. In the case of MFQ, the version translated by Oana Luiza Rebega and Irina Pitică, Livia Apostol (retranslation) from the https://moralfoundations. org/questionnaires/ was applied, and for MCT it was used the Lind-Chicu (2004) version, provided by its author.

\subsection{Research design and procedure}

The study was exploratory, transversal, comparative - i.e., gender, level of education - and correlational - i.e., factors from MFQ and MCT, while the selection of the sample was non-probabilistic.

The two questionnaires were applied on a number of 982 students during class hours, under supervision, during 2019. The questionnaires were applied anonymously (coded) by their teachers, as a practical application of theories thought on classes. The participants have received activity points for their voluntary participation, and were informed by further use of the data. The data was analyzed according to authors' instructions: those respondents who failed the two dummy questions for MFQ and those with less than one missing answer for MCT were excluded. In order to ensure a better relevance of the data that could have been strongly distorted by the age difference, the answers of the middle school students were not retained for the analysis, these being used later for the validation of MCT and comparative analyses. The final database included 739 subjects: 509 (68.87\%) female, 230 (31.12\%) male, age 14 to 54 years ( $94 \% 15$ to 25 years, $M=19.34, S D=5,232$ ), education level: 452 (61.25\%) high school students, 287 (38.8\%) university students. 


\section{Research Results}

For MFQ the results of Romanian students were significantly higher scores than those of American original study in the evaluation of moral foundations, both globally and on the two subscales, especially on "biding" foundation. Female subjects higher average scores than male subjects on all moral foundations (have statistically significant, excepting "in-group/loyalty" foundation), and their scores were higher also on both sub-scales. At the same time, the subjects have higher score on judgment subscale than on relevance subscales all foundations. Comparing the scores of high-school and university students, the same tendency was noticed, the university students having significantly higher scores on all moral foundations.

These results were consistent with those obtained for moral orientation scores assessed by MCT: the high school students had statistically significant lower scores than that of the university student population. An unexpected result was the statistically significant lower score at moral competence for the university student population than for the high school students, the average difference being 3.8 points $\left(\mathrm{M}_{\text {highschool }}=22.0, \mathrm{SD}=\right.$ 15.03 compared to $\mathrm{M}_{\text {university }}=18.2, \mathrm{SD}=12.98$ ). In other words, university students have higher moral orientations and higher scores on all moral foundations, but lower levels of moral competence.

In the case of female subjects, the difference of moral competence $\mathrm{C}$-index is even more statistically significant from high school to university, with an average decrease of 4.3 points from 21.8 to 17.5 , from high school to university, compared to only 2.9 points for male subjects (from 22.5 to 19.6).

According to the initial hypothesis, the analysis of the correlations between the moral orientation and the moral foundations (Kendall's tau_b two-tailed) shows a slight positive correlation with the "individualizing" foundations $(\tau=.048, p=.042,1$-tailed). In addition, those with moral orientations corresponding to stages 1 and 2 are receptive only to the foundations of the "community" ("loyalty" and "authority"), those from level 3 onwards being receptive to all 5 moral foundations (Table 1).

\begin{tabular}{|l|c|c|c|c|c|c|c|c|}
\hline & \multirow{2}{*}{ O M.O. } & \multicolumn{7}{|c|}{ Moral orientations } \\
\cline { 3 - 8 } & & Orient 1 & Orient 2 & Orient 3 & Orient 4 & Orient 5 & Orient 6 \\
\hline Moral foundation & & \multicolumn{7}{|c|}{5 factors } \\
\hline Care & .028 & .018 & -.004 & $.065^{*}$ & $.075^{* *}$ & $.090^{* *}$ & $.121^{* *}$ \\
\hline Fairness & .042 & .019 & .013 & $.083^{* *}$ & $.067^{*}$ & $.095^{* *}$ & $.139^{* *}$ \\
\hline Loyalty & -.005 & $.062^{*}$ & $.064^{*}$ & $.111^{* *}$ & $.100^{* *}$ & $.090^{* *}$ & $.112^{* *}$ \\
\hline Authority & .001 & $.102^{* *}$ & $.067^{*}$ & $.075^{* *}$ & $.060^{*}$ & .051 & $.077^{* *}$ \\
\hline Purity & -.008 & .035 & $.075^{* *}$ & $.073^{* *}$ & $.073^{* *}$ & $.069^{* *}$ & $.089^{* *}$ \\
\hline & & & & 2 factors & & $.151^{* *}$ \\
\hline Individualizing & .048 & .023 & .004 & $.085^{* *}$ & $.077^{* *}$ & $.106^{* *}$ & $.093^{* *}$ & $.112^{* *}$ \\
\hline Biding & -.009 & $.079^{* *}$ & $.088^{* *}$ & $.102^{* *}$ & $.094^{* *}$ & $.093^{*}$ \\
\hline
\end{tabular}




\begin{tabular}{|l|c|c|c|c|c|c|c|c|}
\hline Progressivism & $.059^{*}$ & $-.058^{*}$ & $-.088^{* *}$ & -.027 & -.024 & .034 & .013 \\
\hline & & \multicolumn{7}{|c|}{3 factors } \\
\hline Autonomy & .048 & .023 & .004 & $.085^{* *}$ & $.077^{* *}$ & $.106^{* *}$ & $.151^{* *}$ \\
\hline Community & -.005 & $.096^{* *}$ & $.078^{* *}$ & $.106^{* *}$ & $.093^{* *}$ & $.081^{* *}$ & $.105^{* *}$ \\
\hline Divinity & -.008 & .035 & $.075^{* *}$ & $.073^{* *}$ & $.073^{* *}$ & $.069^{* *}$ & $.089^{* *}$ \\
\hline
\end{tabular}

Kendall's tau_b two-tailed ${ }^{1}$

* Correlation is significant at the 05 level (2-tailed)

** Correlation is significant at the .01 level (2-tailed)

Note: M.O. - moral orientation

Table 1: Correlations between Moral Foundations and Moral Orientations.

This observed correlations' pattern is more obvious in terms of relevance subscales than the judgment ones in the case of the five foundations (except for "purity"). The preference for "autonomy" foundations is consistent with increasing moral orientation, whilst those in moral stages 3 and 4 , corresponding to conventional level of moral orientation, are mostly receptive to "solidarity" foundations.

The analysis of gender differences shows a much greater consistency in the use of the five moral foundations for female subjects (in particular, to female high school subjects, i.e., higher moral competence), compared to male subjects where this consistency has not been manifested more than in the case of the last two moral orientations.

This result is supported by the education level analysis where the consistency in the use of all five moral foundations is found in high school students (with higher moral competence score), but not in university students (lower moral competence score).

In order to have a better image of the correlations between the moral foundations and the moral level the moral orientations was grouped on the three original foundations on which they were built, i.e. the preconventional, the conventional and the postconventional level. The analysis of the correlations with the moral foundations highlights the fact that the preconventional level does not correlate with the person-centered moral foundations ("harm" and "fairness,") instead they are more oriented towards the foundation of "authority" and "loyalty". Conventionally-oriented people are also more receptive to the aspects of "solidarity," while those who prefer post-conventional orientations are receptive to both sets of values ("individualization" and "solidarity") in a greater extent, to the fundamentals of the latter ("harm" and "fairness"). Table 2 shows the correlations between moral foundations and the level of moral orientation.

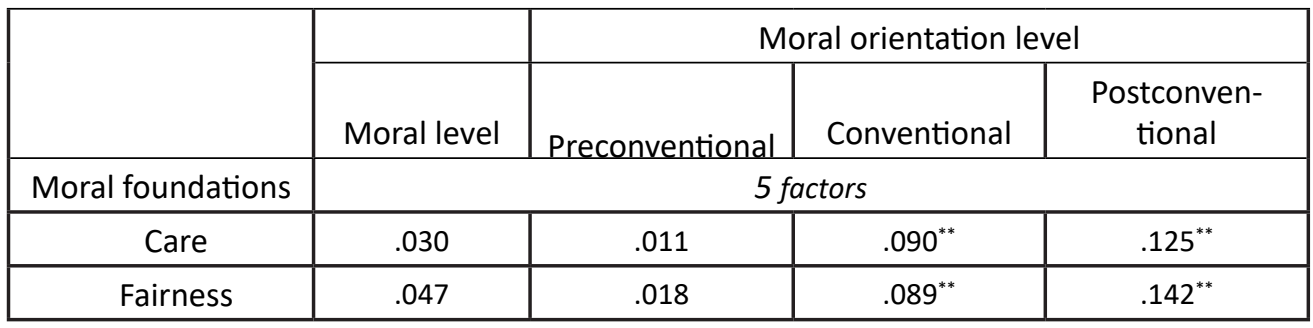

1 The Kendall's $\tau$ b test was preferred over the Spearman's rank correlation $\rho$ because in the literature there are opinions that claim that it would perform better on larger samples (see Zar 1996, 392). 


\begin{tabular}{|c|c|c|c|c|}
\hline Loyalty & -.010 & $.072^{* *}$ & $.130^{* *}$ & $.109^{* *}$ \\
\hline Authority & -.004 & $.099^{* *}$ & $.091^{* *}$ & $.074^{* *}$ \\
\hline \multirow[t]{2}{*}{ Purity } & -.007 & $.066^{*}$ & $.089^{* *}$ & $.086^{* *}$ \\
\hline & \multicolumn{4}{|c|}{2 factors } \\
\hline Individualizing & .051 & .016 & $.100^{* *}$ & $.154^{* *}$ \\
\hline Biding & -.008 & $.098^{* *}$ & $.124^{* *}$ & $.113^{* *}$ \\
\hline \multirow[t]{2}{*}{ Progressivism } & $.074^{*}$ & $-.088^{* *}$ & -.034 & .035 \\
\hline & \multicolumn{4}{|c|}{3 factors } \\
\hline Autonomy & .051 & .016 & $.100^{* *}$ & $.154^{* *}$ \\
\hline Community & -.010 & $.101^{* *}$ & $.127^{* *}$ & $.103^{* *}$ \\
\hline Divinity & -.007 & $.066^{*}$ & $.089^{* *}$ & $.086^{* *}$ \\
\hline
\end{tabular}

Table 2: Correlations between Moral Foundations and Moral Level.

The correlations between moral foundations and the level of moral orientation are stronger in the case of those with a high level of moral competence than in the case of those with a low level of orientation, which is an indication that the relationship between intuitive foundations of moral judgment and moral orientations is influenced by moral competence. Table 3 compares the correlations between moral foundations and the level of moral orientation.

\begin{tabular}{|c|c|c|c|c|c|c|c|c|}
\hline & \multicolumn{4}{|c|}{ C-index $<20$} & \multicolumn{4}{|c|}{ C-index $>20$} \\
\hline & $\mathrm{M}_{\text {level }}$ & Prec. & Conv. & Postc. & $\mathrm{M}_{\text {level }}$ & Prec. & Conv. & Postc. \\
\hline $\begin{array}{c}\text { Moral } \\
\text { foundation }\end{array}$ & & & & & 5 factors & & & \\
\hline Care & ,011 & ,012 & ,080* &, $087^{*}$ & ,061 & 015 &, $104^{* *}$ &, $193^{* *}$ \\
\hline Fairness & ,034 &,- 001 &, $095^{* *}$ &, $128^{* *}$ &, $084^{\dagger}$ & ,029 &, $091^{*}$ &, $194^{* *}$ \\
\hline Loyalty & ,017 & ,042 &, $084^{*}$ & ,073* &,- 048 &, $111^{* *}$ & , $190^{* *}$ &, $169^{* *}$ \\
\hline Authority &,- 025 & ,046 & ,061 & ,055 & ,055 &, $142^{* *}$ &, $142^{* *}$ &, $153^{* *}$ \\
\hline \multirow[t]{2}{*}{ Purity } &,- 009 & 053 &, $090^{* *}$ &, $060^{\dagger}$ & ,011 & ,054 &, $092^{*}$ &, $151^{* *}$ \\
\hline & & & & & 2 factors & & & \\
\hline Individualizing & ,030 & ,005 &, $091^{* *}$ &, $113^{* *}$ &, $092^{\dagger}$ & ,025 &, $117^{* *}$ &, $235^{* *}$ \\
\hline Biding &,- 004 &, $063^{\dagger}$ &, $100^{* *}$ &, $083^{*}$ & ,004 &, $125^{* *}$ &, $159^{* *}$ &, $187^{* *}$ \\
\hline \multirow[t]{2}{*}{ Progressivism } & , $079^{*}$ &,- 048 &,- 006 & ,049 & ,058 &,$- 114^{* *}$ &,$- 068^{\dagger}$ & ,005 \\
\hline & & & & & 3 factors & & & \\
\hline Autonomy & ,030 & ,005 &, $091^{* *}$ &, $113^{* *}$ &, $092^{\dagger}$ & ,025 &, $117^{* *}$ &, $235^{* *}$ \\
\hline Community &,- 005 &, $056^{\dagger}$ &, $087^{* *}$ &, $077^{*}$ &,- 003 &, $144^{* *}$ & ,189** &, $173^{* *}$ \\
\hline Spirituality &,- 009 & ,053 &, $090^{* *}$ &, $060^{+}$ & ,011 & ,054 &, $092^{*}$ &, $151^{* *}$ \\
\hline & & $\begin{array}{l}{ }^{*} \text { Correla } \\
{ }^{* *} \text { Correla } \\
{ }^{+} \text {Correl }\end{array}$ & $\begin{array}{l}\text { dall's tau } \\
\text { is signifi } \\
\text { is signifi } \\
n \text { is signi }\end{array}$ & $\begin{array}{l}\text { two-taile } \\
\text { int at the. } \\
\text { int at the. } \\
\text { ant at the }\end{array}$ & 5 level (2-ta & & & \\
\hline
\end{tabular}

Note: $\mathrm{Ml}_{\text {evel }}$ - moral level, Prec. - preconventional, Conv. - conventional, Postc. - postconventional

Table 3: The relationship between moral foundations and the level of moral orientation according to the level of moral competence. 
Regarding moral competence, the analysis showed negative correlations with the foundation of "authority" and "purity" / "spirituality," "biding" and "community" and positive with "progressivism". These correlations, as was hypothesised, were due only to the scores on the judgment sub-scales (on relevance sub-scale no significant correlation was found), which were statistically significant along the lines of "authority", "purity", "solidarity", and "community".

For female subjects, only a positive correlation was found between moral competence and "progressivism" and a negative with "authority," and for male subjects negative correlations with "authority" and "purity".

For high school students only "progressivism" correlated positively, but in a slight way, with the index of moral competence, and for university students there was a negative correlation with "purity".

Regarding the differences in the use of moral foundations according to the moral competence index (C-index), the analyses showed statistical differences only in the case of the "authority" foundation where those with low index appeal to a greater extent $\left(\mathrm{M}_{\text {clow }}\right.$ $=2.89$ compared to $\mathrm{M}_{\text {Chigh }}=2.78$ ).

Regarding the level of education, the only statistically significant difference was the one related to the "purity" / "spirituality" foundation in the case students $\left(\mathrm{M}_{\text {clow }}=3.12\right.$, $\mathrm{M}_{\text {Chigh }}=2.83$ ).

The correlations between moral foundations and the level (low or high, cut-off point C-index $=20$ ) of the moral competence index according to the level of moral orientation, it was also analyzed. It was found a relationship between the level of moral competence and the tendency of subjects - with conventional and postconventional moral orientations - to use more consistently all five moral foundations. The analysis of the correlation patterns on the two subscales (relevance and judgment) reveals that those with conventional and postconventional moral orientations and high index of moral competence display higher correlations between orientations and judgments, compared to those with low index of moral competence.

\section{Discussion}

Being mostly an exploratory study, extensive analyses were performed, beyond the initial hypotheses that were suggested by theoretical claims and the previous few studies. The aim was to make visible the more nuanced and subtle possible relations between the structure of moral intuitions and the moral orientations, in relation to the moral competence.

For the Social Intuitionist Model of moral judgment, moral intuitions are automated moral judgments, laden with affective valence (good-bad, like-dislike) and opposed to conscious and intentional process of reflective deliberation of moral reasoning (Haidt 2001, 818). 
For the Dual Aspect Model of Moral Behavior, the moral orientations and the moral judgment are aspects of the moral behavior, not components, as suggested by Lind (2016, 51). Moral intuitions and the moral orientations seem to share both emotional roots and cognitive schema, which are unconscious and automated. Even though the trends of correlations were low, they were in line with the predicted second hypothesis. From the perspective of a "bijective" correlation, the firsthypothesis is confirmed only partially. There were negative correlations between the level of moral competence and foundations and a negative correlation with those of "solidarity", "authority" and "purity". These correlations were due exclusively, as theoretically predicted, to the subscales of the judgment. This represents a supporting argument for the convergence of the measurements of the two instruments. On the other hand, there was no correlation between moral competence and the foundations of "individualisation" ("care" \& "correctness") neither globally, nor on the two sub-scales (relevance, respectively judgment).

The second hypothesis was largely confirmed. Moral competence has a weak moderating effect on correlations between moral foundations and moral orientations, according with the predicted pattern. The moral orientations corresponding to the conventional level correlate most strongly with those of the "solidarity" foundations, and those corresponding to the postconventional level with the "individualisation" foundation. This is in agreement with other studies in the field; see, for example, Glover et al. (2014). The difference from previous studies was that correlations were identified at all stages corresponding to the conventional and postconventional moral level.

The moral competence correlates negatively, but only with the subscale of judgment, for the foundations of "authority" and "purity" of MFQ. As we have seen, the subscales of the "relevance" of MFQ is closer to the explicit reasoning within moral reasoning, expressing self-theory or second-order opinion about the criteria underlying one's own moral judgment or how people believe that moral judgments are, and because of this are affected by subjectivism and self-image. This would be an indication that maturation, unaccompanied by a development of moral competence, can lead to a dissociation between moral self-image and moral character.

On the other side, the results are promising because they suggest the possible inappropriateness of "bijective modular approach" on moral judgment mechanisms and, especially, of the relations between moral intuitions (emotion and unconscious reasoning) and moral reasoning.

The extensive analysis of the relations between the moral orientations and the moral foundations allowed exploring possible more complex relations than the "modular" ones ( 1 to 1 types), between these constructs within the moral judgment. The results support a new hypothesis, contrary to the one argued by Trups-Kalne \& Dimdins (2017), who claimed that due to the increase in analytical complexity, an impairment of moral competence is manifested. My findings suggest that it seems that those with high moral competence are more able to operate consistently (principally) with all types of values/ 
intuitions and not vice versa. Indeed, the MFQ hypothesis, by itself, is not "an adequate measure to capture a more advanced moral functioning" as Glover et al. (2014) claims. It is not, also, representative at all for those at the preconventional and conventional stages of the development of moral judgment, as Maxwell and Beaulac (2013) argue.

It seems that the conclusions of the aforementioned studies are the result of "Procrustean bed" of moral psychological research, which neglect or diminish the relevance of semantic dimension of moral reasoning. One of the main shortcomings of mainstream cognitive theories on moral judgment is the dichotomy, in fact, antinomic perspective on conscious/unconscious, intuition/cognition, reason/emotion. The moral intuition is definitely more than automatic emotional reaction and comprise more cognition (heuristics) than most of the perspectives suggests. (Dubljević \& Racine 2014) The other limitation is the negligible value assigned to the semantic aspects. The semantic intervenes at the level of reasoning (Stenning \& van Lambalgen 2004) and emotional arousal or trigger. ${ }^{2}$

As it was proposed by Bucciarelli, Khemlani and Johnson-Laird (2008), the moral affective-cognitive hybrid functioning must not be so coherent and structured as the researchers are trying to make evident. Firstly, they said, there is no necessarily a single criterion of choosing moral propositions from a deontic set of moral principles. Secondly, the mechanisms underlying emotions and deontic evaluations could be very well independent and operate in parallel, and, consequently, some scenarios can elicit emotions prior to moral evaluations, with some other eliciting moral evaluations prior to emotions, and some eliciting them at the same time. Thirdly, the deontic evaluations seem to depend on inferences, either unconscious intuitions or conscious reasoning. And, forth, it is not necessary that a person's beliefs about what is, or isn't, moral to be either complete or consistent.

As Dellantonio and Job (2010) claim, the moral reasoning consists in specific operations not only with the concepts, but mostly on the features, from which these concepts are made of. There seems to be a semantic difference between the Externalized Semantics - conventional and the public dimensions of concepts, which are acquired through language and socialization, and are "characterised by rules whose aim is to assure the possibility of intersubjective communication" (Dellantonio \& Job 2010, 507) and Internalized Semantics - or how information is used by people use (internally, i.e., in their mind) "to carry out categorizations and to understand the linguistic meaning". These two semantics come along with their own negative or positive value, and correspondingly

2 For example, in this research were a high rate of responses under cut-of value for the second dummy question of Moral Foundation Questionnaire ("Whether or not someone was good at math"). In the Romanian version, the term "right" from the questionnaire question "When you decide whether something is right or wrong...," translated as "correct" has its primary sense as "according to the rules in general", and its secondary one emphasis its moral meaning, which seems to be the other way around in comparison to the English meaning for "right". This became obvious when some subjects were questioned about their answer and they mentioned that they have thought it is important to have a developed mathematical, logical ability in order to make something right ("correct"). 
emotions, which can be similar or not.

\section{Limitations}

The Moral Competence Test passed all three psychological criteria of validity: (1) the six type of moral orientations were preferred in a increased order, (2) the parallelism between moral competence and type of moral orientations, and (3) the correlations among the preferences for the six types form a simple structure (Lind 2016). On the other side, the major limitation of the study was the low performance on the studied population of MFQ, which displayed only a low model fit. This could be the result of the authors' strategy for constructing the instrument by focusing on capturing different (theoretical possible) facets of each foundation with the risk of having dissimilar items that correlate moderately, as opposed to achieving high internal consistency (Graham et al. 2011). The very recent analyses increasingly reveal the necessity to amend and improve such instruments for measuring moral values particularly in intercultural research. A systematic content analysis of 539 studies (Tamul et al. 2020, in press) reveals that the mean Cronbach's alpha scores for four of the five subscales of Moral Foundations Questionnaire were below 70. Other studies on the 27 countries spanning the five largest continents found that it is difficult to replicate the five-factor model across a wide variety of populations (Iurino \& Saucier 2020). My own analysis - which is in progress - does suggest that most of the studies take its psychometric properties for granted.

Other possible limitations could result from the application of the questionnaire during class hours. This could contribute to a certain "framing" of the data, given that the power dynamics in the classroom present certain particularities; the answers of the subjects are susceptible to be influenced by the context, the presence of the tenured teacher, the unexpected character of the task, etc.

\section{Conclusions}

There is a concordance, although not powerful, between moral foundations, as measured by MFQ and moral orientations, assessed by MCT. At the same time, the level of moral competence acts as a moderating factor of this correlation between intuitions and orientations. Those people with higher moral competence, i.e., ability to judge consistently with a given set of moral principles, are able to employ more consistently their (educated) moral intuitions. The development of moral cognition is governed by higher schema and the concordance with triggered intuition is moderated by the general level of moral competence. Moral reasoning is not necessarily parallel with the moral intuition. People have the power to educate their moral intuitions, not only to construct moral judgments on top of them. Moral intuitions are rationally amenable and the patterns for automatic judgment foundation could be shaped by episodes of rational reflection (Sauer 2017). 
Moreover, the study suggests a possible explanation for a possible theoretical outcome steaming from how the Moral Competence Test was designed, but which was not found in empirical data, i.e., the possibility of obtaining consistent judgments on low levels of moral orientation. The empirical research showed that this case is not common at all, but there was no explanation why this is happening. My study suggests that is possible that the individuals with low levels of moral orientation are unable to use consistent values/intuitions in their moral judgment. Their axiological reasoning is conjectural; they have no consistent moral system or perspective on their experience. They interpret and employ values/intuitions in their moral judgment according to their motivated reasoning and not as fixed fundamental criteria for judgment. They have no commitment for a certain type of values and judge using any intuitions at hand.

Finally, the results corroborate with those of Stenning and van Lambalgen suggesting that "«massive modularity» in cognition should be treated with some skepticism" (Stenning \& van Lambalgen 2004, 523). The striving to discover innateness, substantial modularity and distinct mechanisms, in moral judgment and reasoning blow in the wind while the cognitive functioning could be more dynamic and hybrid than it is thought. The ability to judge according to higher stages of cognitive moral development does not mean that people will judge each time and/or exclusively in this manner regardless of the context, the experience, motivation, actors, and the particular situation, all influencing moral judgment strategies.

The meta-theoretical assumptions underlying the research in moral psychology are essential for the success of research programs. For reasons of convenience and congruence with methodological constraints of cognitive paradigm, the main research programs work predominantly with a narrow conception of the ethical domain divided between deontological versus utilitarian ethics. But there are other meta-ethical paradigms, as is the virtue ethics. This paradigm, consonant with the image of moral judgments as educated intuitions mentioned earlier, can be more suitable to explain human moral behavior, because this paradigm seems to be able to manage diverse situations with high ethical complexity without appealing to fixed specific rules. Of course, the virtue ethics is intrinsically related to personality, and it conceived as an organic whole and as an enterprise, which could mean that the very personality traits model would need to be enriched. Beside "dispositional traits" of well-established Big Five Model, the new one has to take into account, "individual's unique variation" on the general evolutionary design, "characteristic adaptations" and, most of all, "self-defining "life narratives", which are complexly and differentially situated in culture and social context (McAdams \& Pals 2006). This can explain why moral values are hardly generalizable in various cultures, although theories are found to be universal. "The processes that underlie moral cognition may not be a human universal in any simple sense, because moral systems may play different roles in different cultures" (Sachdeva, Singh, \& Medin 2011). 
Only such comprehensive model seems to be able to accommodate appropriately the intuitions (rooted in the human evolutionary design), the moral orientations (derived from characteristic adaptation), the moral reasoning (influenced by self-narrative "complexly and differentially situated in culture and social context") in a more accurate image of what it is human moral psychology. The scientific paradigms are lenses for our eyes, which can re-present reality only in the way they are capable of. Therefore, there is a necessity to critically examine, not only the theory, instruments and methodology, but also the meta-theory which underlies the very research paradigm. Only in this way, scientific knowledge can provide a rich and appropriate image of the complex tri-unitary phenomenon which is the human being (Popoveniuc 2017).

\section{References}

Bataglia P. U. R., de Morais A., \& Lepre R. M. 2010. “A teoria de Kohlberg sobre o desenvolvimento do raciocínio moral e os instrumentos de avaliação de juízo e competência moral em uso no Brasil" [Kohlberg's theory about moral judgment development and the instruments used for evaluation of moral judgment and moral competence in Brazil,] Estudos de Psicologia 15(1):25-32.

Bucciarelli M., Khemlani S., \& Johnson-Laird P. N. 2008. "The Psychology of Moral reasoning," Judgment and Decision Making 3(2):121-139.

Candee D. 1976. "Structure and Choice in Moral Reasoning," Journal of Personality and Social Psychology 34:1293-1301.

Greene J. D., Nystrom L. E., Engell A. D., Darley J. M., \& Cohen J. D. 2004. “The Neural Bases of Cognitive Conflict and Control in Moral Judgment," Neuron 44(2):389400.

Dellantonio S. \& Job R. 2010. "Morality According to a Cognitive Interpretation: A Semantic Model for Moral Behavior," in L. Magnani, W. Carnielli, \& C. Pizzi (Eds.), Model-Based Reasoning in Science and Technology. Studies in Computational Intelligence, Vol. 314. Springer: Berlin - Heidelberg.

Dellantonio S. \& Job R. 2012. “Moral Intuitions vs. Moral Reasoning. A Philosophical Analysis of the Explanatory Models Intuitionism Relies On," in L Magnani \& L. Ping (Eds.), Philosophy and Cognitive Science. Western \& Eastern Studies (pp. 239-262). Springer.

Diessner R., Mayton D., \& Dolen M. A. 1993. "Values Hierarchies and Moral Reasoning," The Journal of Social Psychology 133(6):869-871.

Dubljević V. \& Racine E. 2014. "The ADC of Moral Judgment: Opening the Black Box of Moral Intuitions with Heuristics About Agents, Deeds, and Consequences," $A J O B$ Neuroscience 5(4):3-20. 
Emler N. 2002. "Morality and Political Orientations: An Analysis of Their Relationship," European Review of Social Psychology 13:259-291.

Ellemers N., van der Toorn J., Paunov Y., \& van Leeuwen T. 2019. “The Psychology of Morality: A Review and Analysis of Empirical Studies Published from 1940 through 2017," Personality and Social Psychology Review 23(4):332-366.

Feldman G. 2020. "Personal Values and Moral Foundations: Examining Relations and Joint Prediction of Moral Variables." (Unpublished manuscript, available at https://osf.io/6qs5g/, lact accessed on April 10, 2021).

Fishkin J., Keniston K., \& McKinnon C. 1973. "Moral Reasoning and Political Ideology," Journal of Personality and Social Psychology 27(1):109-119.

Gay J., Vitacco M., Hackney A., Beussink C., \& Lilienfeld S. 2018. "Relations among Psychopathy, Moral Competence, and Moral Intuitions in Student and Community Samples," Legal and Criminological Psychology 23:117-134.

Graham J., Haidt J., Koleva S., Motyl M., Iyer R., Wojcik S., \& Ditto P. H. 2013. “Moral Foundations Theory: The Pragmatic Validity of Moral Pluralism," Advances in Experimental Social Psychology 47:55-130.

Graham J., Haidt J., \& Nosek B. A. 2009. "Liberals and Conservatives Rely on Different Dets of Moral Foundations," Journal of Personality and Social Psychology 96(5):1029-1046.

Graham J., Nosek B. A., Haidt J., Iyer R., Koleva S., \& Ditto P. H. 2011. "Mapping the Moral Domain," Journal of Personality and Social Psychology 101:366-385.

Greene J. D., Nystrom L. E., Engell A. D., Darley J. M., \& Cohen J. D. 2004. “The Neural Bases of Cognitive Conflict and Control in Moral Judgment," Neuron 44(2):389400

Gross M. L. 1996. “Moral Reasoning and Ideological Affiliation: A Cross-national Study," Political Psychology 17(2):317-338.

Haidt J. 2001. "The Emotional Dog and Its Rational Tail: A Social Intuitionist Approach to Moral Judgment," Psychological Review 108(4):814-834.

Haidt J. 2012. The Righteous Mind: Why Good People are Divided by Politics and Religion. Pantheon Books: New York.

Haidt J. 2013. "Moral Psychology for the Twenty-first Century," Journal of Moral Education 42(3):281-297.

Haidt J. \& Graham J. 2007. "When Morality Opposes Justice: Conservatives Have Moral Intuitions that Liberals May Not Recognize," Social Justice Research 20:98-116.

Helkama K. 1982. "The Development of Moral Reasoning and Moral Values," Acta Psychologica Fennica 9:99-111.

Ishida C. 2006. "How do Scores of DIT and MJT Differ? A Critical Assessment of the Use of Alternative Moral Development Scales in Studies of Business Ethics," Journal of Business Ethics 67(1):63-74. 
Iurino K. \& Saucier G. 2020. "Testing Measurement Invariance of the Moral Foundations Questionnaire Across 27 Countries," Assessment 27(2):365-372.

Jussim L. 1986. "Self-fulfilling Prophecies. A Theoretical and Integrative Review," Psychological Review 93(4):429-445.

Kohlberg L. 1964. “Development of Moral Character and Moral Ideology," in M. L. Hoffman \& L. W. Hoffman (Eds.), Review of Child Development Research. Vol. I (pp. 381-431). New York, NY: Russel Sage Foundation.

Kohlberg L. 1981. Essays in Moral Development. Vol. I, The Philosophy of Moral Development. New York: Harper \& Row.

Kohlberg L. 1984. Essays in Moral Development. Vol. II, The Psychology of Moral Development. New York: Harper \& Row.

Lan G., Gowing M., McMahon S., Fritz R., \& Norman K. 2008. "A Study of the Relationship between Personal Values and Moral Reasoning of Undergraduate Business Students," Journal of Business Ethics 78(1-2):121-139.

Lan G., Gowing M., Rieger F., McMahon S., \& King N. 2010. "Values, Value Types and Moral Reasoning of MBA Students," Business Ethics: A European Review 19(2):183-198.

Lind G. 2016. How to Teach Moral Competence. $1^{\text {st }}$ Ed. Berlin: Logos Verlag.

Lind G., Sandberger J. U., \& Bargel T. 1985. “Moral Competence and Democratic Personality," in G. Lind, H. A. Hartmann, \& R. Wakenhut (Eds.), Moral Development and the Social Environment (pp. 55-78). New Jersey: Precedent Publishers.

Maxwell B. \& Beaulac G. 2013. "The Concept of the Moral Domain in Moral Foundations Theory and Cognitive Developmental Theory: Horses for Courses?" Journal of Moral Education 42(3):360-382.

McAdams D. P. \& Pals J. L. 2006. “A New Big Five. Fundamental Principles for an Integrative Science of Personality," American Psychologist 61(3):204-217.

Monin B., Pizarro D. A., \& Beer J. S. 2007a. "Deciding Versus Reacting: Conceptions of Moral Judgment and the Reason-Affect Debate," Review of General Psychology 11(2):99-111.

Monin B., Pizarro, D. A., \& Beer, J. S. 2007b. "Emotion and Reason in Moral Judgment: Different Prototypes Lead to Different Theories," in K. D. Vohs, R. F. Baumeister, \& G. Loewenstein (Eds.), Do Emotions Help or Hurt Decision Making?: A Hedgefoxian Perspective (pp. 219-244). New York: Russell Sage Foundation Press.

Nassi A. J., Abramowitz S. I., \& Youmans J. E. 1983. “Moral Development and Politics a Decade Later: A Replication and Extension," Journal of Personality and Social Psychology 45(5):1127-1135.

Nisbett R. E. \& Wilson T. D. 1977. “Telling More Than We Can Know: Verbal Reports on Mental Processes," Psychological Review 84(3):231-259.

Ostini R. \& Ellerman D. 1997. "Clarifying the Relationship between Values and Moral Judgment," Psychological Reports 81(2):691-702. 
Pohling R., Bzdok D., Eigenstetter M., Stumpf S., \& Strobel A. 2016. "What is Ethical Competence? The Role of Empathy, Personal Values, and the Five-factor Model of Personality in Ethical Decision-making," Journal of Business Ethics 137(3):449474.

Popoveniuc B. 2017. "Evoluția psihologiei și structura trinitară a personalității” [The evolution of psychology and the trinitarian structure of personality], in Filosofia și perspectiva umană. Chișinău: UnAȘM, Biotehdesign.

Raaijmakers Q. A. W., Verbogt T. M. A., \& Volleberg W. A. M. 1998. "Moral Reasoning and Political Beliefs of Dutch Adolescent and Young Adults," Journal of Social Issues 54(3):531-546.

Rest J. R. 1983. “Morality,” in P. H. Mussen (Ed.), Manual of Child Psychology. $4^{\text {th }}$ Ed., Vol. 3 (pp. 495-555). New York: Wiley.

Rest J. R., Narvaez D., Thoma S. J., \& Bebeau M. J. 1999. “DIT2: Devising and Testing a Revised instrument of Moral Judgment," Journal of Educational Psychology 91(4):644-659.

Rokeach M. 1973. The Nature of Human Values. New York: The Free Press.

Sauer H. 2017. Moral Judgments as Educated Intuitions: A Rationalist Theory of Moral Judgment. MIT Press.

Sachdeva S., Singh P., \& Medin D. 2011. "Culture and the Quest for Universal Principles in Moral Reasoning," International Journal of Psychology 46(3):161-176.

Schwartz S. H., Cieciuch J., Vecchione M., Davidov E., Fischer R., Beierlein C., Ramos A., Verkasalo M., Lönnqvist J.-E., Demirutku K., Dirilen-Gumus O., \& Konty M. 2012. "Refining the Theory of Basic Individual Values," Journal of Personality and Social Psychology 103:663-688.

Shweder R. A., Much N. C., Mahapatra M., \& Park L. 1997. "The 'Big Three' of Morality (Autonomy, Community, Divinity) and the 'Big Three' Explanations of Suffering," in A. M. Brandt \& P. Rozin (Eds.), Morality and Health (pp. 119-169). Abingdom on Thames: Taylor \& Frances/Routledge.

Simpson E. 1987. “The Development of Political Reasoning," Human Development 30(5):268-281.

Stenning K. \& van Lambalgen M. 2004. "A Little Logic Goes a Long Way: Basing Experiment on Semantic Theory in the Cognitive Science of Conditional Reasoning," Cognitive Science 28(4):481-529.

Tamul D., Elson M., Ivory J., Hotter J., Lanier M., Wolf J., \& Martínez-Carrillo N. 2020. „Moral Foundations' Methodological Foundations: A Systematic Analysis of Reliability in Research Using the Moral Foundations Questionnaire” (in press). Available at https://psyarxiv.com/shcgv/ (Last accessed on April 21, 2021).

Trups-Kalne I. \& Dimdins G. 2017. "Relation between Social Conservatism, Moral Competence, Moral Orientations, and the Importance of Moral Foundations," Mediterranean Journal of Social Sciences 8(6):81-90. 